\title{
III
}

\section{LA REVISTA IBEROAMERICANA Y LA HORA PRESENTE}

Decia Brenes Mesén que el Instituto Internacional de Literatura Iberoamericana "se propone coordinar y revelar el sentido de la obra literaria de América" y que los hombres encargados de publicar la REVIST A IBEROAMERICANA, que no "han jurado pleitesía a escuela o agrupación alguna", quieren servir, leal, desinteresada $e$ independientemente, inspirándose en "una misma comprensión de cuanto implica la unidad espiritual de todas nuestras nacionalidades", $\sin$ exclusiónes de ninguna clase.

Es éste nuestro programa.

En París, en la Habana, en Santiago de Chile, en Buenos Aires, en Bogotá y en otros lugares, se han organizado ya instituciones semejantes a la nuestra, y se persiguen idénticos fines y objetos. Quienes aman la Hispanidad eterna, en sus varias manifestaciones culturales, buscan el modo de servirla, y se afanan por llegar a un acercamiento justo, comprensivo y eficaz y por destruír el aislamiento en que se hallan - sobre todo en Américalos hombres más llamados a luchar juntos, perjudicándose así notablemente y retardando la obra de cultura continental que, hasta el presente oscurecida e ignorada, de- 
be brillar como merece $y$ ha de difundirse sin trabas ni miedos de ninguna índole.

La REVIST A IBEROAMERICANA no aspira a ejercer ninguna rectoría mental ni estética, sino a servir un ideal cultural que a todos nos alienta e ilumina. Su anhelo es hallar los valores literarios donde se encuentren, defenderlos y afirmarlos con calor y lealtad, $y$, sin seguir rumbo alguno político ni religioso, recoger esos valores metódicamente, para honrarlos y enaltecerlos.

Por eso la REVISTA IBEROAMERICANA, una vez más, les hace a todos los intelectuales que aman la joven cultura iberoamericana un llamamiento a colaborar en su publicación; a los autores, para que nos envien sus obras oportunamente y con ellas los estudios y trabajos que le den realce a sus páginas, y a los demás, para que nos apoyen en la obra felizmente iniciada y que, gracias a la buena acogida que ha recibido, irá ampliándose en lo porvenir.

El Instituto Internacional de Literatura Iberoamerica$n a$, y la revista que es su órgano oficial, en su afán de servir la causa de la cultura iberoamericana, quieren también honrar a quienes mejor la representan. Por lo mismo, vienen luchando porque en las sesiones del Segundo Congreso Internacional de Catedráticos de Literatura Iberoamericana se le haga al Maestro Baldomero Sanín Cano un homenaje continental. Hoy es Sanín Cano el elegido. Mañana será otro. Y después otros también.

$\mathrm{Y}$ quiere la REVISTA IBEROAMERICANA extenderles su cordial invitación a colaborar en ella no sólo a los hombres de América, sino a los de allende el mar que tengan fe en su destino y se sientan animados por el deseo de depurar y fortalecer los vínculos espirituales que la unen a la brillante tradición cultural que a ella vino del Viejo Mundo. 
Por quererlo, la REVIST A IBEROAMERICANA acoge con placer la carta que el doctor González, Presidente del Instituto, les dirigió a algunos intelectuales espanoles, y se honra con la publicación de los estudios que tres de ellos nos enviaron ya con gesto de generosa y alta comprensión que agradecemos profundamente.

\section{Los Angeles, California}

11 de agosto de 1939.

Scñores

Amado Alonso

Américo Castro

Enrique Diez-Canedo

T. Navarro Tomás

Federico de Onís y

Pedro Salinas.

Ilustres colegas y amigos:

Con algunos de ustedes he dialogado sobre los temas que van a ser objeto de estas líneas, y dolido de que la distancia no me permitiera hacer lo mismo con todos, nació en mí la idea de esta especie de broadcasting epistolar.

El Instituto Internacional de Literatura Iberoamericana -y los órganos de publicidad y de trabajo que lo integran- surgió a la vida del espiritu como una organización compuesta de hombzes y mujeres interesados específicamente en la cultura iberoamericana. La moderna necesidad de la división del trabajo y su consecuencia práctica, la especialización, imponen la aparente limitación que el hombre de nuestra institución sugiere; pero su espíritu es amplísimo y no excluye -antes invita y acoge con especial simpatía - a todos los que de dicha cultura se preocupan.

II. 
El evidente desarrollo que en los últimos cincuenta años ha alcanzado la literatura de Iberoamérica y el interés cada día mayor que por su estudio y conocimiento se nota, lo mismo en la América nuestra que en la anglosajona, hacían necesaria la creación de este Instituto. La literatura iberoamericana -usemos el término en su valor de cómoda fórmula, sin pretensiones de exactitudevoluciona rápidamente hacia una mayor originalidad, y a medida que sus características locales se perfilan, necesariamente se distancia más de España y de la modalidad espiritual que la literatura española comporta. Es éste un proceso, no sólo inevitable sino deseable. Mientras esta diferenciación espititual no sea profunda y radical, América no dejará de ser colonia intelectual. Pero esta evolución que pudiéramos denominar biológica no implica antagonismo ni mucho menos divorcio entre la cultura peninsular y la que en América se gesta, sino variedad, integración y complemento. En mi concepto, cuanto más evolucionemos en América hacia una cultura propia, que sea expresión auténtica de nuestra naturaleza, de nuestro paisaje y de nuestra idiosincrasia americana, y a la vez reflejo de nuestra madurez espiritual, más cerca nos encontraremos de la corriente cultural más valiosa que España ha producido: la popular. Ejemplo de esto es el magnífico renacimiento del romance que desde hace años se viene operando en casi toda la América, ya en forma de corridos mexicanos, ya en otras manifestaciones más estilizadas como las que encontramos en la Argentina, Chile, el Uruguay, etc. Nunca en América se llevó más lejos el espíritu local y la originalidad expresiva que en las diversas formas artísticas en que se plasmó el alma gauchesca $y$, sin embargo, nunca estuvo más próxima a la corriente popular española ninguna otra expresión estética de cuantss por acá se han producido. 
No hay, pues, a mi entender, incompatibilidad ni antagonismo entre el necesario desarrollo de la originalidad americana y la buena tradición española. La raíz de la cultura iberoamericana se halla en España y Portugal y es necesario que mantengamos - superándola- la continuidad de esta tradición. España y América, lejos de excluirse, en mi concepto se integran y se complementan, como ya lo apunté. España, divorciada de América, quedaría trunca y despojada del hecho cultural más universal y trascendente de su historia, y una América reñida con España o que pretendiese -como algunos han propugnado- romper con o desconocer su abolengo y raigambre iberos - si tal cosa fuese posible- sería un advenedizo de la cultura, sin entronque con la fecunda corriente humanística del renacimiento y "sin solar conocido", como decía Rodó. Lo que necesitamos, por consiguiente, es mutua comprensión y respeto y un concepto más amplio y comprensivo del hecho cultural hispano en sus múltiples aspectos y manifestaciones.

España dejó de ser la metrópoli intelectual de América durante las dos últimas décadas del siglo XIX. A partir de entonces, América se ha manumitido culturalmente, sin perjuicio de las fecundas influencias recíprocas que ambas literaturas han experimentado desde entonces. Así el saludable influjo que los poetas de América ejercieron en las postrimerías del siglo pasado y en los años iniciales del presente sobre los bardos peninsulares y el que posteriormente han producido en América hombres como Unamuno, Menéndez Pidal, Ortega y Gasset, García Lorca, etc.

Es éste un maridaje fecundo y deseable que sólo puede manifestarse entre culturas adultas o en vía de madurez. América entra ahora en su pubertad intelectual y empieza a producir obra original, pobre de formas toda- 
vía porque carece de una tradición de disciplina humanistica seria y sostenida, pero está ya en posesión de un espíritu autóctono. Formas y lenguas tendrán que ser europeas, pero el mensaje es terrigeno y el alma que su obra alienta es americana. Después del deslumbramiento cosmopolita finisecular, y del momentáneo mimetismo de postguerra - limitado este último a los poetas que nada propio tenian que ofrecer- la obra de creación en América se encauza por los rumbos de la tradición ibera. Y dentro de esta continuidad histórica caben todas las innovaciones y las mayores audacias, como apuntaba Alfonso Reyes hace algún tiempo. Querámoslo o no, el único entronque cultural de recia vitalidad que la América tiene es el que la une a Europa y principalmente a la península ibérica. Los factores psicológicos y artísticos que el indio, el negro, el italiano, etc., representan, pigmentarán nuestra obra, pero no podrán desviarla de su proyección histórica. Serán como la sal y la pimienta que le añadirán originalidad y color, pero nunca podrán desvirtuar el hecho - consumado ya desde el siglo XVII - de una cultura plasmada en los moldes europeos. Nuestra órbita cultural la marcaron España y Portugal durante la época colonial, y todo esfuerzo por desviarla en lo esencial será vano y perdido. Creo que las mentes más lúcidas y mejor orientadas de América se dan cuenta cabal de la inevitabilidad de esta orientación y la aceptan, unos con gozo, otros acaso a regañadientes, pero todos acatan el linaje y la trayectoria iberos como los únicos viables. La cultura de América, si ha de alcanzar algún dia patente de originalidad, estimo que lo logrará mediante la evolución superada de la tradición ibera. Dentro de esta tradición y profundamente enraizados en ella se han producido en América sus más auténticos valores, que han sido también los más fuertes y originales. Esto sin perjuicio de que 
algunos negaran y hasta renegaran de España y de su política. Mas en esta misma apasionada y denostadora actitud demostraron que procedian de la más pura cepa española y como españoles legítimos se conducian. Pienso en Bello, Lizardi, Heredia, Sarmiento, Montalvo, Palma, Caro, Cuervo, Silva, Martí, Darío, Rodó, Varona y tantos otros, para no citar sino a los ya desaparecidos.

América vive actualmente un instante gestador en el que pugna por encontrar su ruta y dar expresión a su espíritu. Sufre, por otra parte, las consecuencias de la encrucijada intelectual y del caos moral del mundo en estos años de postguerra. Está desorientada, pero busca afanosa un rumbo y una meta. Sobre su incipiente cultura y sobre su rudimentaria organización económica y social se proyectan, desde casi todos los puntos de la rosa de los vientos, poderosas influencias y subterráneas ambiciones de imperialismo económico que se disfrazan con el barniz de la cultura. Ha de vivir, pues, alerta y ha de forjar. vigilante su propio destino, sin dejarse seducir por los cantos de sirena con que tratan de engatusarla los que codician su riqueza virgen. En esta misma pugna con que se la disputan varios imperialismos solapados, encontrará probablemente nuestra América su propia defensa, de la misma manera que la doncella solicitada a la vez por varios seductores acaba por hacerse inmune a todos. El peligro real consistiría en entregarse confiada a uno solo; pero creo que vamos rebasando ya esta etapa y este riesgo.

$\mathrm{Y}$ en este momento crucial que vivimos, el intelectual que, como ustedes, conoce nuestra América y la comprende y se interesa por su cultura y por su porvenir, y ve con simpatía y con espíritu comprensivo su tesonero esfuerzo por definirse y ser, substantivamente, puede ayudarnos mucho con su labor. Todos ustedes han roto con aquella desdichadísima actitud peyorativa de la mayoría 2 * 
de los escritores y de los académicos españoles del siglo pasado, y continúan el esfuerzo armonizador y fecundo de don Juan Valera, de don Marcelino Menéndez y Pelayo y de don Miguel de Unamuno. Por eso, en mi nombre y en el del Instituto, quiero invitarles muy especialmente -y como a ustedes a todos los demás intelectuales españoles que estiman las glorias de América y propician el desarrollo de su cultura- a que colaboren en la tarea que el Instituto y su vocero principal, la REVIST A IBEROAMERICANA, se proponen realizar. Glosando a uno de los más clarividentes guías de América, diré que aspiramos a que nuestra obra se haga "con todos y para el bien de todos". El espíritu que nos anima está ya definido en el simbolismo y en la leyenda de nuestro sello oficial. $\mathrm{Ni}$ el Instituto de Literatura Iberoamericana ni la REVISTA $I B E R O A M E R I C A N A$ vienen a rivalizar ni a duplicar la labor que otras meritísimas organizaciones y publicaciones llevan a cabo; en todo caso la complementarán. Ambos están al servicio de la cultura iberoamericana y aspiran a ser índice aglutinante de la misma. Magno empeño. Mas para realizarlo, contamos con la buena voluntad de los escritores de América y' de España. Y entre los últimos nadie con más ilustres credenciales ni con mejores títulos que ustedes.

Estimo que las relaciones entre América y España habrán de cimentarse sobre un concepto de consanguinidad cultural y no sobre relaciones de orden político y sobre vagos parentescos raciales o afinidades religiosas. Los conceptos de raza, política y religión están hoy al servicio de intereses económicos, y por lo mismo se han desprestigiado tanto que ya casi nadie los toma en cuenta. Pero la cultura es un valor superior y permanente, $y$ aunque en el caos actual esté también subordinada en algunas partes al interés económico, tarde o temprano recuperará sus 
fueros. Y en nuestro caso creo que es el valor esencial; por lo menos debe serlo para los que a su libre desarrollo nos consagramos.

Esta es nuestra aspiración. Ustedes que, como Dario. son americanos de España y españoles de América, sabrán comprenderla y alentarla con su colaboración y con su simpatía. Que ambas - simpatía y colaboración- nos sirvan de estímulo para perseverar en la tarea felizmente iniciada.

De ustedes muy cordial admirador y amigo,

Manuel Pedro González. 
